\title{
Transition from Traditional to Outcome Based Education- A Case Study
}

\author{
*Lizzie D'cruz \\ Lecturer (Selection Grade), Department of Electronics and Communication Engineering, Dr. B. R. Ambedkar \\ Institute of Technology, Port Blair, Andaman and Nicobar Islands, India. \\ Corresponding Author: Lizzie D'cruz
}

\begin{abstract}
Outcome Based Education (OBE) is growing at an astounding rate throughout the world. The required skill set and knowledge after Diploma to become an Engineer is obtained by effective teaching of the Engineering Education. Due to growing technological advancement \& with the use of internet and social networking, education system has made lots of innovativeness in teaching learning system which has led the present day engineers to compete globally with new challenges. In the traditional system of education, teachers put the full attention on what they teach rather than on what the students are learning, OBE emphasizes on what is expected from the student when they complete their course rather than how they have achieved. Transition in the outcome based education gives the Institutes a profoundly different means of restructuring the teaching learning process. This paper gives an overview of learner centered learning system introduced in the subject VLSI Design of Electronics and Communication Engineering Branch. Learning \& teaching activities that would facilitate students' achieving the Intended Learning Outcomes were designed and assessment tasks were evaluated. The transition from $3 R$ 's (Reading, writing, Arithmetic) to $4 C^{\prime}$ 's (Creativity, Critical, thinking, Communication \& Collaboration) made a sea difference in course attainment. The result of $C O$ attainment shows that transformation from the traditional teaching learning to learner's centric approach has given the desired attributes, leading to the conclusion that the OBE approach introduced was a success.
\end{abstract}

Keywords: Outcome Based Education, VLSI Design, Electronics and communication Engineering, technological advancement.

Date of Submission: 01-07-2017

Date of acceptance: 15-07-2017

\section{Introduction}

The transition from output based education to Outcome based education is the demand of $21^{\text {st }}$ century learning system. This is a model which not only gives much better technical knowledge to $21^{\text {st }}$ century Engineers but also gives emphasis on development of affective domain attributes which are needed in workplace e.g. Interpersonal skills, strong work ethics, motivation \& initiative, flexibility/ adaptability analytical skills, Computer skills, organizational skills, leadership skills, self confidence friendly/outgoing personality, well mannered / polite, creativity, entrepreneurial skills. Indian Education System has introduced the Outcome Based Education System through National Board of Accreditation (NBA). An OBE system addresses the competency requirement of Diploma students, and then organizes the curriculum, instruction and assessment to make sure this learning ultimately happens. The Institution has obtained NBA accreditation which encourages quality improvement initiatives, self evaluation, accountability and innovation. The four basic principles as per Spady, 1994 are clarity of focus, designing down, high expectations and expanded opportunities. Thus for implementing the OBE system, it is very essential to first to determine the desired outcome and then as per the outcome, curriculum, delivery \& assessment system and support facilities are planned. During the Course delivery, different method are introduced to make learning and teaching more effective and to obtain the desired course outcome attainment. This paper gives an overview about the process followed for implementing outcome based Education in Dr. B.R. Ambedkar Institute of Technology. the subject VLSI Design wherein the details about the method used in learning teaching process and also the assessment method used for attainment of course outcome is discussed.

\section{Model of Outcome Based education system}

National Board of Accreditation has made the guidelines for the Institution undergoing accreditation for quality assurance \& excellence. The outcome based education is the in build mandatory requirement for accreditation. Each programme is supported by program educational Objectives, program specific objectives, Program Outcomes, Course outcomes \& intended learning outcome for all Course. All affiliating Institution offering OBE, carry out gap assessment in the curriculum and provide additional coaching hour for teaching the 
additional content. The program Education objectives, Program Specific Objectives and program outcomes prepared by the Electronics and Communication Department of Dr. B.R. Ambedkar Institute of Technology is given below. PO's are written in line with the graduate attributes listed in NBA Manual.

II.1 Program Educational Objective- PEO's are the statements which describe the professional achievements of the students in five years after completion of Diploma.

PEO1: To establish as a competent engineer in Electronics, Communication and allied Industries.

PEO2: To pursue higher studies for advance learning and understanding in an ever widening sphere of technology.

PEO3: To became an entrepreneur in electronics.

PEO4: Aspire knowledge and capabilities with high ethical, professional standards through life Long learning, experiences and responsible to community needs.

II.2 Program Specific Objective- PSO's are the statements which describes what the students should be able to do in their specific field after completion of Diploma program.

PSO 1: To demonstrate knowledge and understanding of engineering concepts and apply these to the industries.

PSO 2: Troubleshoot analog \& digital circuits or systems for a given specification and function.

II.3 Program Outcome- PO's are the statements which describes what the students should be able to do after completion of Diploma program.

PO-1: Apply the knowledge of basic mathematics, science and technological practice in Electronics and Communication engineering. (Basic knowledge)

PO-2: Apply discipline \& specific knowledge to identify, formulate and analyze engineering problem methodically to reach proper conclusions. (Discipline knowledge)

PO-3: Plan and perform experiments and practices to use the results to solve engineering problems. (Experiments and practice)

PO-4: Investigate \& locate the faults in complex engineering problems by using different diagnostic tools. (Engineering Tools)

PO-5: Apply reasoning informed by contextual knowledge to assess societal, health, safety, legal \& cultural issues \& the consequent responsibilities relevant to professional engineering practice. (The engineer and society)

PO-6: Assess the impact of technical decisions on sustainable development of society and environment. (Environment and sustainability)

PO-7: Adapt strong ethical and professional responsibility and adherence to quality. (Ethics)

PO-8: Participate effectively in all activities as an individual \& as a member or leader in student centric committee \& in multidisciplinary works. (Individual and team work)

PO-9: Communicate effectively through reports, presentations and discussions within both the technical domain and the community at large. (Communication)

PO-10: Involve in information search \& self-learning activities. (Life - long learning)

II.4 Course Outcome- CO's are the statements which describes what the students should be able to do after completion of a Course. The course Outcome of VLSI Design Course is listed below

CO1 Identify different Moore and Mealy models based on the logical condition

CO2: Develop CMOS chip using the knowledge of CMOS fabrication process.

CO3: Check the syntax of the program for the given digital systems.

CO4: Develop program to implement combinational and sequential logic circuit using VHDL.

CO5: Test the output of the given program using simulation and synthesis process

CO6: Select the suitable IC for a given application based on the knowledge of specification and properties. 


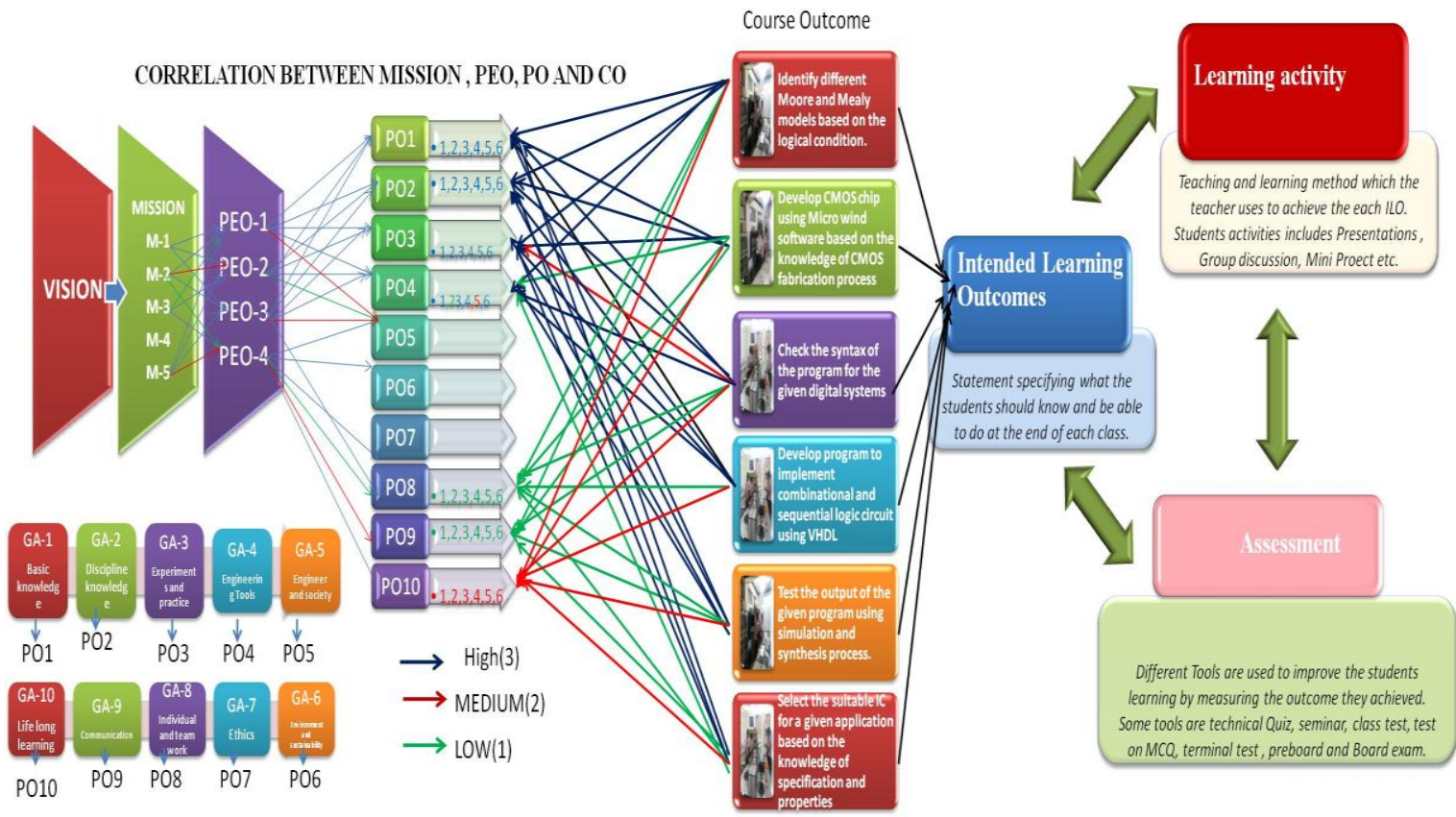

Figure1: Outcome Based Process Model with its correlation

The vision is the Institution's road map, indicating what the Institution wants to become in 10 years time with guided transformational initiatives \& by setting a defined direction for the Institution's growth. To achieve the Vision, Missions are set. In an Educational Institution, program Education objectives, Program Specific Objectives are planned to achieve the Mission. To achieve the objectives Course Outcome attainment and Program Outcome attainments are calculated. As the implementation of outcome based Education system is a Compliance driven activity, a full commitment from the faculty is also required along with documented process for its success.

\section{Course attainment of the course VLSI design}

\section{III.1 Approach followed for Course Outcome Attainment}

The approach followed for CO attainment for the subject VLSI Design is depicted in the flow diagram which is offered in the final year Diploma of Electronics and Communication Engineering Department of Dr. B. R. Ambedkar Institute of Technology. Co attainment is calculated by the students performance in internal and Board examination.

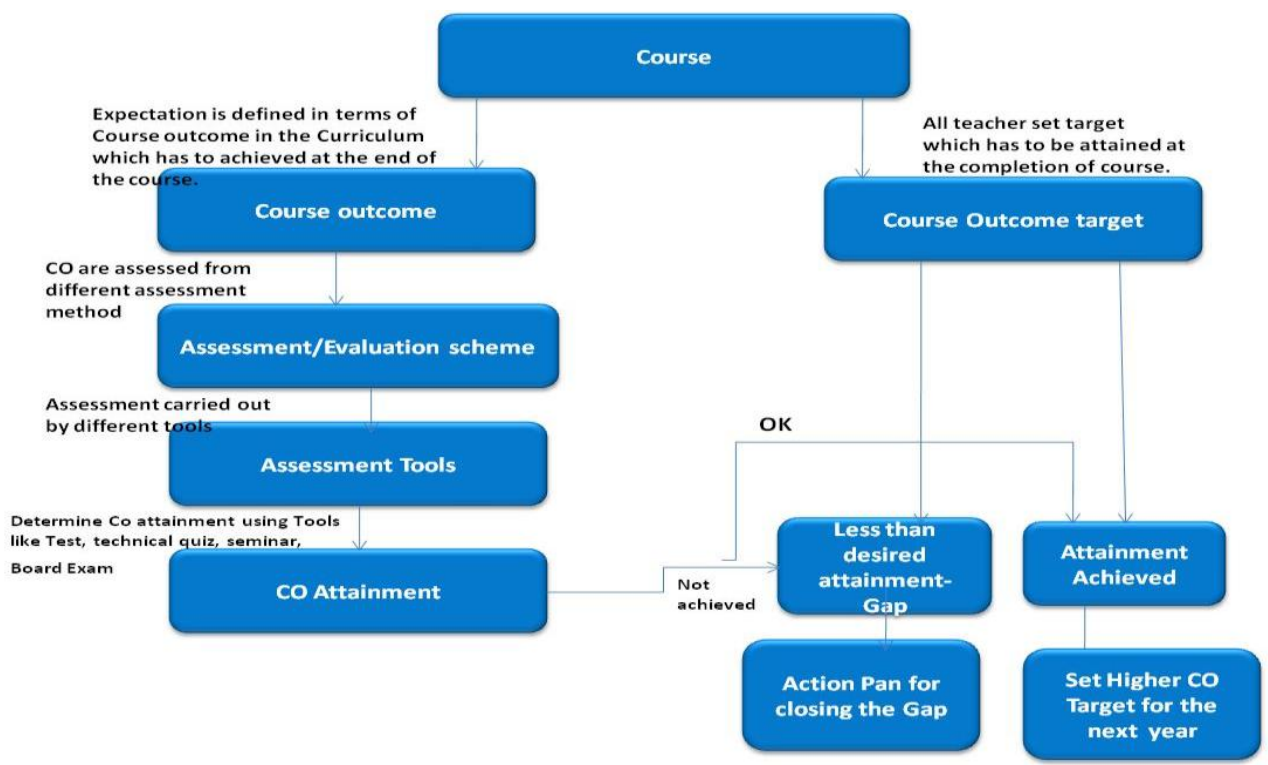

Figure2: Course attainment Process 


\section{III.2 Approach followed for Program Outcome Attainment}

Po attainment is carried out by direct and indirect method. Exit Survey, Course completion survey Faulty survey is carried out in the direct method. Questionnaires were prepared and provided to students of final year of Electronics and Communication Engineering Department and calculated the PO weightage attainment and percentage. Similarly for the course completion survey, questionnaires were prepared and provided to students and from the data, weightage attainment \& percentage calculated. Finally faculty survey carried out. $80 \%$ is taken from the direct measurement and $20 \%$ from all the surveys conducted.

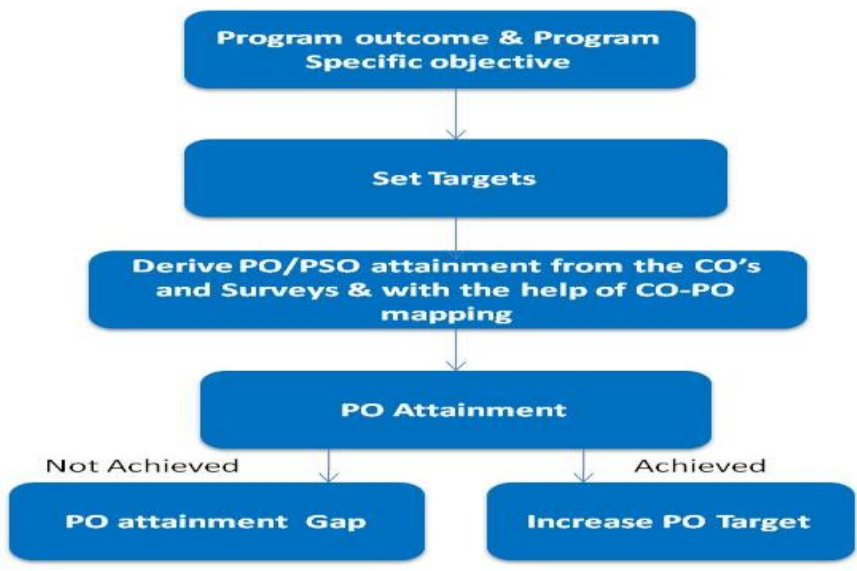

\section{III.3 CO-PO Mapping}

Figure3: Program attainment Process

The PO's /PSO's are mapped with Course that are offered in the Electronics and Communication Engineering Programme. Program Outcomes emphasizes the expectations of students from their Diploma Programme. Attainment of PO/PSO depends on the mapping strength and Co Attainment. Mapping strength reflected CO-Po mapping is defined in three levels. High (3), Medium (2) \& Low (1). Method used for allotting the mapping strength depends on the number of hours given for a particular $\mathrm{CO}$ which addresses the given PO. Co-Po mapping is shown below wherein the mapping strength levels are kept as 1 for low, 2 for medium and 3 for High. "-" has been put for no correlation.

\begin{tabular}{||l|c|c|c|c|c|c|c|c|c|c|c|c||}
\hline COs & PO 1 & PO 2 & PO 3 & PO4 & PO 5 & PO 6 & PO 7 & PO 8 & PO 9 & PO 10 & PSO1 & PSO2 \\
\hline $\begin{array}{l}\text { 1. Identify different Moore and Mealy } \\
\text { models based on the logical condition. }\end{array}$ & 3 & 3 & 3 & 3 & - & - & - & 1 & 1 & 2 & 3 & 3 \\
\hline $\begin{array}{l}\text { 2. Develop CMOS chip using the } \\
\text { knowledge of CMOS fabrication } \\
\text { process. }\end{array}$ & 3 & 3 & 3 & 1 & - & - & - & 1 & 1 & 2 & 2 & 3 \\
\hline $\begin{array}{l}\text { 3. Check the syntax of the program } \\
\text { for the given digital systems. }\end{array}$ & 2 & 3 & 3 & 3 & - & - & - & 1 & 1 & 2 & 3 & 3 \\
\hline $\begin{array}{l}\text { 4. Develop program to implement } \\
\text { combinational and sequential logic } \\
\text { circuit using VHDL. }\end{array}$ & 3 & 3 & 3 & 3 & - & - & - & 1 & 1 & 2 & 3 & 2 \\
\hline $\begin{array}{l}\text { 5. Test the output of the given } \\
\text { program using simulation and } \\
\text { synthesis process. }\end{array}$ & 3 & 3 & 3 & 3 & - & - & - & 1 & 1 & 2 & 3 & 3 \\
\hline $\begin{array}{l}\text { 6. Select the suitable IC for a given } \\
\text { application based on the knowledge of } \\
\text { specification and properties. }\end{array}$ & 3 & 3 & 3 & 2 & & - & - & 1 & 1 & 2 & 2 & 3 \\
\hline \begin{tabular}{l} 
Course Outcome \\
\hline
\end{tabular} & 3 & 3 & 3 & 3 & - & - & - & 1 & 1 & 2 & 3 & 3 \\
\hline
\end{tabular}

Table III. 3. 1 CO-PO Mapping

\section{III.4 Internal Assessment scheme}

For internal assessment, tools like class test, Assignment, technical Quiz, laboratory test, MCQ test are conducted. $80 \%$ weight age of the Students performance in Board examination and $20 \%$ weightage of internal Marks is taken for total assessment. Therefore the attainment calculation will be $80 \%$ of obtained attainment in Board exam $+20 \%$ of obtained attainment in internal assessment. The Evaluation tools with Course outcome wise weight age in the test is tabulated below 


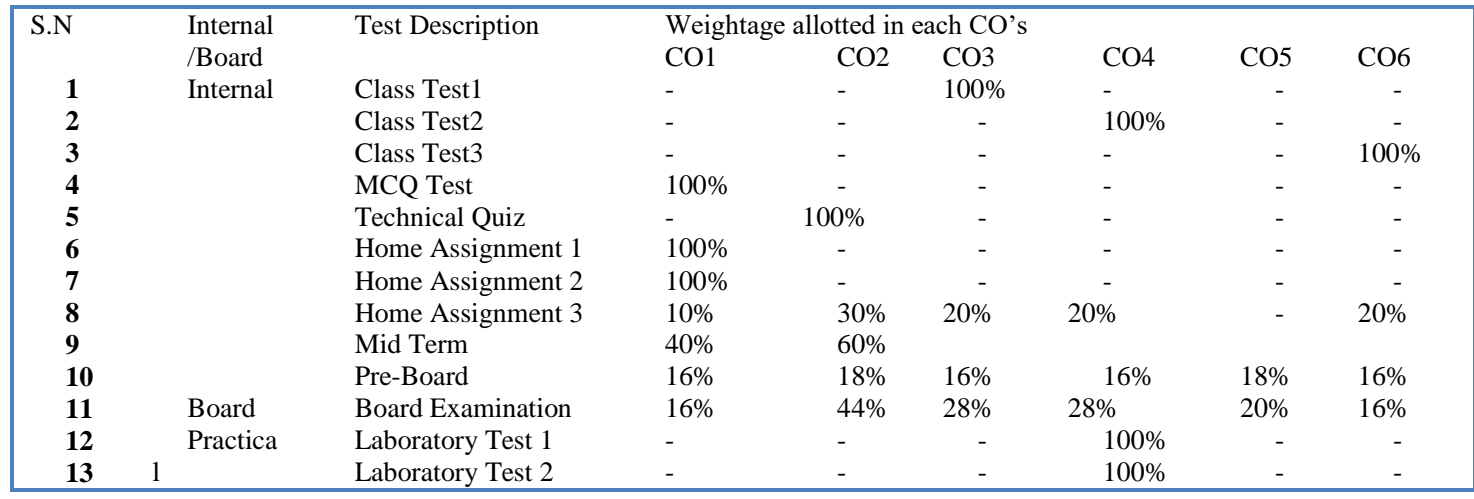

Class test, MCQ Test, Technical quiz \& lab test are added and will be converted into $10 \%$ weightage. Home Assignment is added and is converted into 10\% weightage. From the Mid Term 30\% \& $70 \%$ of PreBoard is taken \& from the total $80 \%$ weightage is taken. The addition of class test head (10\%), Home Assignment head (10\%) and 80\% from Mod Term and Pre Board will form the internal assessment.

\section{III.5 Course attainment for the subject VLSI Design}

For calculating of Course attainment of internal exam and Board Exam, first the class average is taken. The number of students (counts) is total number of students above the class average. Calculation of attainment is carried out with same attainment level indicated as example in self assessment report of NBA and obtained the attainment as zero. Attainment levels were Attainment level1- 60\% students more than class average, Attainment level2 - 70\% students more than class average and $80 \%$ students more than class average. Department level meetings were conducted for finalizing the attainment level criteria. The CO-Po assessment carried out with new attainment levels. The new Attainment levels are 35\% of students getting more than class average, $45 \%$ of students getting more than class average and $55 \%$ of student getting more than class average and $55 \%$ of students getting more than class average

\begin{tabular}{|c|c|c|c|c|c|c|c|c|c|c|c|c|c|c|c|c|c|c|c|}
\hline Name & Mid T & & Pre 1 & ard & & & & & Hon & Assi & ment & & & $\begin{array}{l}\text { Class } \\
\text { test }\end{array}$ & ests/ T & chnica & Quiz/ & & $\begin{array}{l}\text { Pr } \\
\text { Test }\end{array}$ \\
\hline CO & 1 & 2 & 1 & 2 & 3 & 4 & 5 & 6 & 1 & 2 & 3 & 4 & 6 & 1 & 2 & 3 & 4 & 6 & 4 \\
\hline M.Mark & 8 & 12 & 16 & 18 & 16 & 16 & 18 & 16 & 21 & 3 & 2 & 2 & 2 & 30 & 20 & 5 & 5 & 10 & 25 \\
\hline A & 5.25 & 5.25 & 8 & 5 & 5 & 7.5 & 2.5 & 8.5 & 21 & 3 & 2 & 2 & 2 & 14 & 14.2 & 5 & 5 & 10 & 20 \\
\hline B & 8 & 6 & 8.5 & 2 & 0 & 0 & 0 & 0 & 19 & 3 & 2 & 2 & 2 & 14 & 9.2 & 2 & 2.5 & 9.5 & 22 \\
\hline C & 8 & 11 & 15 & 14 & 12 & 15 & 3.5 & 8.5 & 21 & 3 & 2 & 2 & 2 & 21 & 17 & 5 & 5 & 9.5 & 24 \\
\hline D & 4.5 & 7.5 & 12 & 4.5 & 7.5 & 1.5 & 1.5 & 11 & 19 & 3 & 2 & 2 & 2 & 13 & 11.2 & 3 & 4 & 9.5 & 20 \\
\hline $\mathrm{E}$ & 7.5 & 9.75 & 11 & 13 & 7.5 & 12 & 0 & 0 & 21 & 3 & 2 & 2 & 2 & 15 & 15 & 5 & 5 & 9.5 & 24 \\
\hline F & 8 & 9.75 & 13 & 13 & 0 & 7 & 2.5 & 15 & 19 & 3 & 2 & 2 & 2 & 19 & 14 & 5 & 5 & 10 & 21 \\
\hline G & 8 & 5.75 & 14 & 4 & 7 & 0 & 1 & 10 & 19 & 3 & 2 & 0 & 0 & 16 & 12 & 3 & 4 & 5 & 19 \\
\hline $\mathrm{H}$ & 1.7 & 8.5 & 6.5 & 8 & 7 & 15 & 3 & 0 & 19 & 2 & 2 & 1 & 0 & 10 & 12 & 5 & 5 & 5 & 21 \\
\hline I & 8 & 10.5 & 11 & 16 & 6.5 & 10.5 & 4 & 11 & 20 & 3 & 2 & 2 & 2 & 24 & 15.4 & 5 & 5 & 10 & 21 \\
\hline $\mathrm{J}$ & 8 & 8.5 & 9.5 & 7 & 4.5 & 12.5 & 1 & 6 & 20 & 3 & 2 & 2 & 2 & 23 & 16.4 & 5 & 5 & 9.5 & 22 \\
\hline K & 8 & 7 & 9 & 11 & 3 & 6 & 0 & 1 & 21 & 3 & 2 & 0 & 0 & 21 & 13 & 5 & 5 & 5 & 22 \\
\hline $\mathrm{L}$ & 8 & 8.75 & 8 & 15 & 12 & 11.5 & 3.5 & 6 & 21 & 3 & 2 & 0 & 0 & 23 & 12 & 5 & 5 & 5 & 20 \\
\hline $\mathrm{M}$ & 5.5 & 7.75 & 9 & 5 & 8 & 15 & 19 & 0 & 21 & 3 & 2 & 2 & 2 & 12 & 11 & 5 & 5 & 10 & 22 \\
\hline $\mathrm{N}$ & 0 & 0 & 0 & 0 & 0 & 0 & 0 & 0 & 16 & 2 & 2 & 1 & 0 & 9 & 13 & 0 & 0 & 3.5 & 19 \\
\hline 0 & 5.5 & 6.5 & 7.5 & 13 & 0 & 0 & 1.5 & 0 & 20 & 3 & 2 & 2 & 2 & 16 & 6.5 & 1 & 1.5 & 5 & 19 \\
\hline P & 8 & 7 & 8.5 & 11 & 11 & 11 & 0 & 0 & 21 & 3 & 2 & 0 & 0 & 19 & 16 & 5 & 5 & 4.5 & 23 \\
\hline $\mathrm{Q}$ & 0.25 & 0 & 0 & 0 & 4 & 3.5 & 4 & 0 & 16 & 2 & 2 & 1 & 0 & 12.4 & 0 & 3 & 4 & 10 & 21 \\
\hline $\mathrm{R}$ & 4.5 & 2.5 & 0 & 3.5 & 1.5 & 0 & 0 & 4 & 16 & 3 & 2 & 0 & 0 & 11.5 & 14 & 1 & 0.5 & 1.5 & 17 \\
\hline S & 6.7 & 7.5 & 7 & 14 & 9.5 & 12 & 7 & 0 & 19 & 3 & 2 & 2 & 2 & 18 & 10 & 4 & 4 & 5 & 22 \\
\hline $\mathbf{A v}$ & 5.9 & 6.82 & 8.2 & 8.2 & 5.5 & 7.37 & 2.8 & $\begin{array}{c}4.2 \\
1\end{array}$ & $\begin{array}{c}19 . \\
4\end{array}$ & 2.8 & 2.0 & 1.3 & $\begin{array}{c}1.1 \\
6\end{array}$ & 16.3 & $\begin{array}{c}12 . \\
2\end{array}$ & 4 & 4.0 & 7.2 & $\begin{array}{l}20 . \\
7\end{array}$ \\
\hline $\begin{array}{l}\text { No more } \\
\text { than AV }\end{array}$ & 11 & 12 & 9 & 9 & 10 & 10 & 7 & 8 & 10 & 16 & 19 & 11 & 11 & 8 & 10 & 18 & 18 & 17 & 10 \\
\hline$\%$ & 57.8 & 63.1 & 47 & $\begin{array}{c}47 . \\
4\end{array}$ & $\begin{array}{c}52 . \\
6\end{array}$ & 52.6 & 37 & $\begin{array}{c}42 . \\
1\end{array}$ & $\begin{array}{c}52 . \\
6\end{array}$ & $\begin{array}{c}84 . \\
2\end{array}$ & $\begin{array}{c}10 \\
0\end{array}$ & $\begin{array}{c}57 . \\
9\end{array}$ & $\begin{array}{c}57 . \\
9\end{array}$ & 42.1 & $\begin{array}{c}52 . \\
6\end{array}$ & $\begin{array}{c}52 . \\
6\end{array}$ & 52.6 & 89.5 & $\begin{array}{r}52 . \\
6\end{array}$ \\
\hline $\begin{array}{l}\text { Attainme } \\
\text { nt }\end{array}$ & 3 & 3 & 2 & 2 & 2 & 2 & 1 & 1 & 2 & 3 & 3 & 3 & 3 & 1 & 2 & 2 & & & 3 \\
\hline
\end{tabular}

Table III.5.1 CO attainment for VLSI Design

\begin{tabular}{|c|c|c|c|c|c|c|c|c|}
\hline $\mathrm{CO}$ & $\begin{array}{l}\text { Mid } \\
\text { term }\end{array}$ & $\begin{array}{r}\text { Pre } \\
\text { board }\end{array}$ & $\begin{array}{l}\text { Total of Mid term } \\
\text { \& Pre board }\end{array}$ & HA & CT & pr & $\begin{array}{l}\text { Total of HA, } \\
\text { Ct \& PR }\end{array}$ & $\begin{array}{l}\text { CO } \\
\text { attainment } \\
\text { (Internal) }\end{array}$ \\
\hline 1 & 3 & 2 & 2.3 & 2 & 1 & - & 1.5 & 2.14 \\
\hline 3 & - & 2 & 1.4 & 3 & 2 & - & 2.5 & 1.62 \\
\hline 4 & - & 2 & 2 & - & & 2 & 2 & 2 \\
\hline 5 & - & 1 & 1 & 3 & 2 & - & 2.5 & 1.3 \\
\hline
\end{tabular}

Table III.5.2 Summary of Attainment (Internal) 


\section{Sample Calculation}

i) Total of Mid Term and Pre board $=30 \%$ of Midterm $+70 \%$ of Pre board $=3 * 30 \%+2 * 70 \%$

$$
\begin{aligned}
& =0.9+1.4 \\
& =2.3
\end{aligned}
$$

ii) Total of Home Assignment and test $=(2+1) / 2=1.5$

iii) Total Internal attainment $=80 \%$ of Mid Term and Pre board $+20 \%$ of HA \& Test

$$
\begin{aligned}
& =2.3 * 80 \%+1.5 * 20 \% \\
& =2.14
\end{aligned}
$$

iv) Total Co attainment $=80 \%$ of Board exam attainment $+20 \%$ of internal attainment $=3 * 80 \%+1.8 * 20 \%$

$$
=2.4+0.36=2.76
$$

\section{III.6 End Exam Result of Course-VLSI Design}

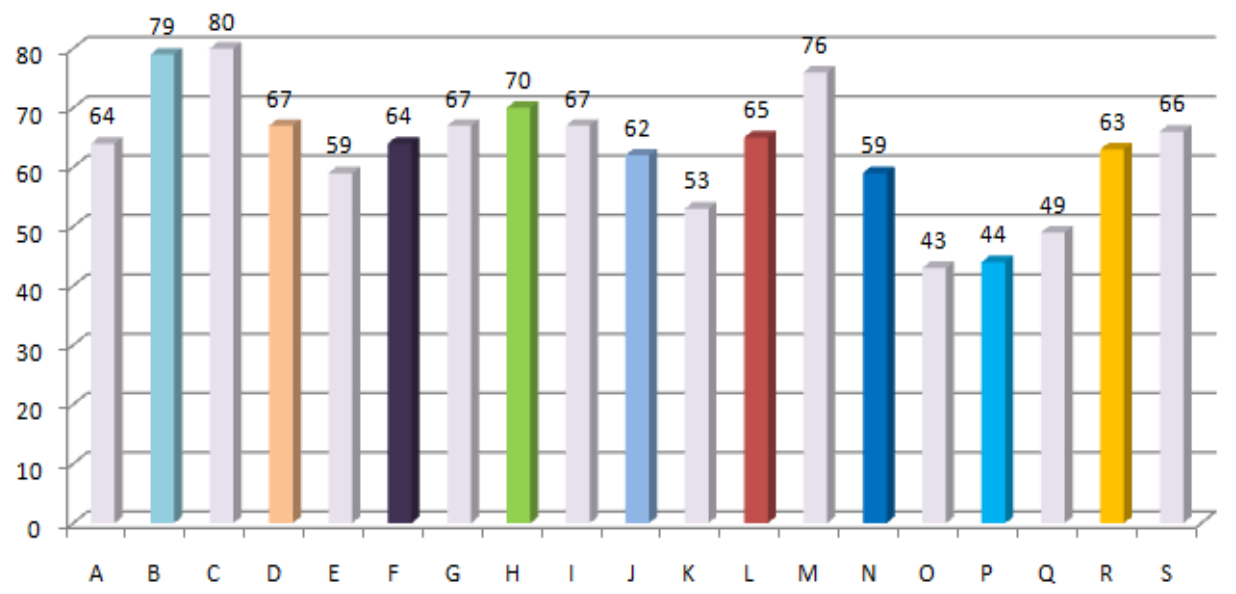

Figure4: End Exam Result

\section{PO Attainment Through Indirect Method}

\section{IV.1 Analysis of Exit Survey Data}

Exit survey was carried out through questionnaire from final year Electronics and Communication Engineering students. Out of the $20 \%$ weightage allotted for indirect method, $10 \%$ is taken from the Exit survey. $5 \%$ weight age allotted for Faculty survey and $5 \%$ for Course completion survey.

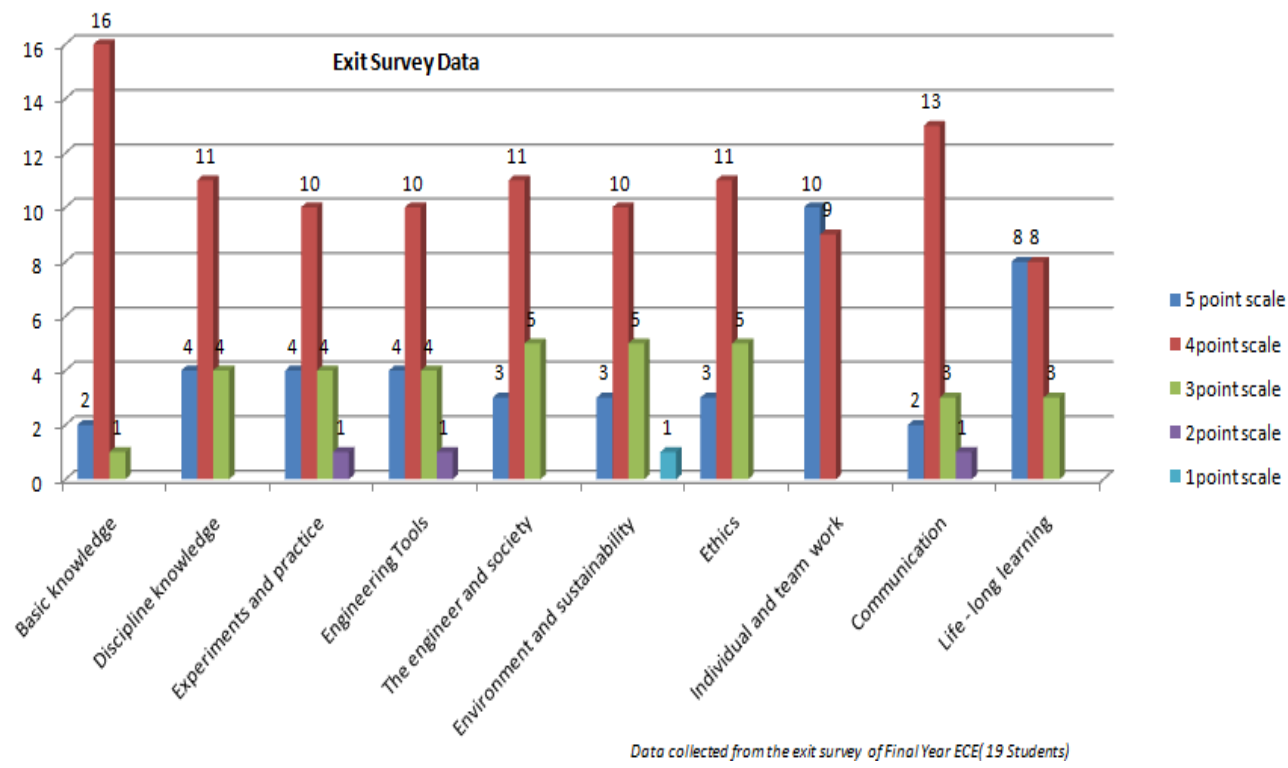

Figure 4: Exit Survey Analysis 
IV.2 Analysis of Faculty Survey Data

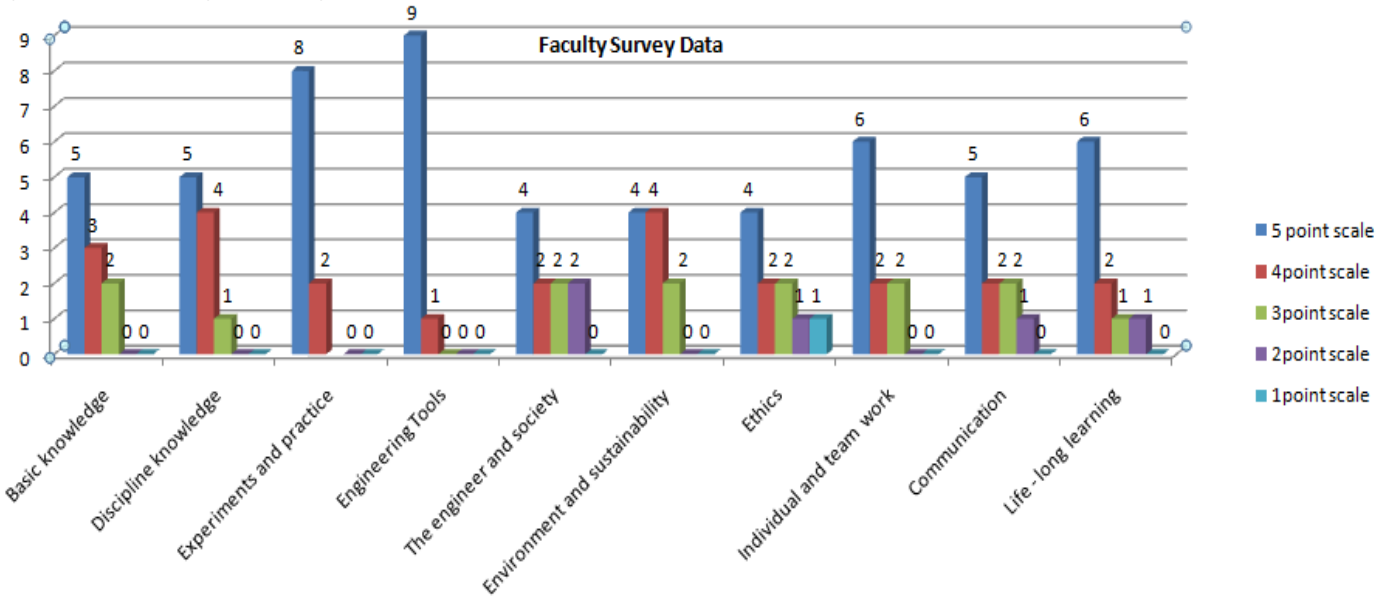

Figure 5 : Faculty Survey Analysis

IV.3 CO- PO Mapping for Sixth Semester

All Courses offered in sixth semester is mapped with PO's/PSO's. Co-Po mapping is shown below wherein the correlation level are kept as 1 for low, 2 for medium and 3 for High. "-" has been put for no correlation.

\begin{tabular}{||l|c|c|c|c|c|c|c|c|c|c|c|c|c|c||}
\hline Name of the subject & PO 1 & PO 2 & PO 3 & PO4 & PO 5 & PO 6 & PO 7 & PO 8 & PO 9 & PO 10 & PSO1 & PSO2 \\
\hline VLSI Design & 3 & 3 & 3 & 3 & - & - & - & 1 & 1 & 2 & 3 & 3 \\
\hline Mobile Communication & 3 & 3 & 3 & 1 & - & - & - & 1 & 1 & 2 & 3 & 3 \\
\hline Embedded System & 3 & 3 & 3 & 3 & - & - & - & 1 & 1 & 2 & 3 & 3 \\
\hline Management & 1 & - & - & - & 1 & 3 & 3 & 2 & 3 & 2 & - & - \\
\hline Advance Communication System & 3 & 3 & 3 & 1 & - & - & - & 1 & 1 & 2 & 3 & 3 \\
\hline Simulation Software & 2 & 3 & 3 & 2 & - & - & - & 1 & 1 & 3 & 2 & 2 \\
\hline Industrial Project & 3 & 3 & 3 & 3 & & & & 2 & 1 & 3 & 3 & 3 \\
\hline
\end{tabular}

Table IV.3.1 CO-PO mapping for Sixth Semester

\section{IV.4 CO-PO Assessment Matrix}

$\mathrm{Co} / \mathrm{Po}$ assessment matrix is obtained from the actual attainment of all course of sixth semester through direct and indirect method. $80 \%$ of attainment through direct and $20 \%$ through indirect method is considered and based on the actual attainment and target set the closer of loop is planned.

\begin{tabular}{|c|c|c|c|c|c|c|c|c|c|c|c|c|}
\hline Name of the subject & PO 1 & PO 2 & PO 3 & PO4 & PO 5 & PO 6 & PO 7 & PO 8 & PO 9 & PO 10 & PSO1 & PSO2 \\
\hline VLSI Design & 2.76 & 2.76 & 2.76 & 2.76 & 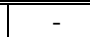 & - & - & 0.92 & 0.92 & 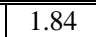 & 2.76 & 2.76 \\
\hline Mobile Communication & 2.01 & 2.01 & 2.01 & 0.67 & - & - & - & 0.67 & 0.67 & 1.34 & 2.01 & 2.01 \\
\hline Embedded System & 3.00 & 3.00 & 3.00 & 3.00 & & & & 1.00 & 1.00 & 2.00 & 3.00 & 3.00 \\
\hline Management & 066 & - & - & - & 0.66 & 1.99 & 1.99 & 1.33 & 1.99 & 1.33 & - & - \\
\hline $\begin{array}{ll}\text { Advance } & \text { Communication } \\
\text { System } & \\
\end{array}$ & 1.86 & 1.86 & 1.86 & .62 & & & & 0.62 & 0.62 & 1.24 & 1.86 & 1.86 \\
\hline Simulation Software & 2.00 & 3.00 & 3.00 & 2.00 & - & - & - & 1.00 & 1.00 & 3.00 & 2.00 & 2.00 \\
\hline Industrial Project & 1.99 & 1.99 & 1.99 & 1.99 & & & & 1.33 & 0.66 & 1.99 & 1.99 & 1.99 \\
\hline $\begin{array}{l}\text { Total Co-PO attainment } \\
\text { through Direct method }\end{array}$ & 2.04 & 2.43 & 2.43 & 1.84 & 0.66 & 1.99 & 1.99 & 0.98 & 0.98 & 1.82 & 2.27 & 2.27 \\
\hline $\begin{array}{l}80 \% \text { of Co-PO attainment } \\
\text { through Direct method }\end{array}$ & 1.63 & 1.94 & 1.94 & 1.47 & 0.52 & 1.59 & 1.59 & 0.78 & 0.78 & 1.45 & 1.81 & 1.81 \\
\hline $\begin{array}{lll}\text { Indirect Method- } & \text { Exit } \\
\text { Survey }(10 \%) & & \\
\end{array}$ & 2.7 & 2.7 & 3 & 3 & 2.4 & 2.4 & 2.4 & 2.7 & 2.4 & 2.7 & 2.4 & 2.4 \\
\hline $\begin{array}{l}\text { Indirect Method- Faculty } \\
\text { Survey }(5 \%)\end{array}$ & 2.4 & 2.4 & 2.4 & 2.4 & 2.4 & 2.4 & 2.4 & 3 & 2.4 & 2.4 & 2.4 & 2.4 \\
\hline $\begin{array}{l}\text { Indirect Method- Course } \\
\text { Completion Survey }(5 \%)\end{array}$ & 2.4 & 2.4 & 2.4 & 2.4 & 2.4 & 2.4 & 2.4 & 3 & 2.4 & 2.4 & 2.4 & 2.4 \\
\hline $\begin{array}{l}\text { Total Co-PO attainment } \\
\text { through indirect method }\end{array}$ & 2.5 & 2.5 & 2.6 & 2.6 & 2.4 & 2.4 & 2.4 & 2.9 & 2.4 & 2.5 & 2.4 & 2.4 \\
\hline $\begin{array}{l}20 \% \text { of Co-PO attainment } \\
\text { through indirect method }\end{array}$ & 0.5 & 0.5 & 0.52 & 0.52 & 0.48 & 0.48 & 0.48 & 0.58 & 0.48 & 0.5 & 0.48 & 0.48 \\
\hline Total Po Attainment & 2.13 & 2.44 & 2.46 & 1.99 & 1.14 & 2.07 & 2.07 & 1.36 & 1.26 & 1.95 & 2.29 & 2.29 \\
\hline PO Target Set( assumed) & 2 & 2 & 2 & 1.5 & 1.00 & 2 & 2 & 1 & 1 & 1.5 & 2 & 2 \\
\hline $\begin{array}{llll}\begin{array}{l}\text { Achievement status of } \\
\text { attainment }\end{array} & & \\
\end{array}$ & $\mathrm{Y}$ & $\mathrm{Y}$ & $\mathrm{Y}$ & $\mathrm{Y}$ & $\mathrm{Y}$ & $\mathrm{Y}$ & $\mathrm{Y}$ & $\mathrm{Y}$ & $\mathrm{Y}$ & $\mathrm{Y}$ & $\mathrm{Y}$ & $\mathrm{Y}$ \\
\hline
\end{tabular}

Table IV. 4.2 Co-Po Assessment Matrix 


\section{IV.5 Corrective Action - Closing the Quality Loop}

"closing the loop" is a essential step for all process for improvement. Deming's Quality Cycle is a useful Model which can be used for closing the loop. First step in quality circle is to plan all the activities and document it in the course plan. Secondly all the activities enlisted in course plan is executed and then measure the performance i.e check and finally calculate the achievement, initiate appropriate action commencing the next round of the quality cycle. If the attainment is not achieved as per the planned target, we need to further analyze the reasons for the same and plan suitable corrective actions for the next round and if the achievement exceeds the planned target, then set higher target level. Analyses are to be carried out to check whether target set was realistic or it was very easy to achieve.

This concept of Quality Loop operates at all levels of attainment i.e CO attainment, PO/PSO attainment. At course level, after the course delivered completely the actual attainment is calculated and if it is less then suitable improvements in the teaching /learning process is done to increase the actual attainment so as to reach the target. If the actual attainment is achieved then loop is closed by increasing the new target level. Same process is followed for PO/PSO \& PEO attainment after delivering the whole program. This concept applies even at higher levels also i.e Mission and Vision but the time frames are usually larger. The Mission is revisited typically once in 5 to 6 years. The vision is revisited not less than about 7 to 10 years.

\section{Conclusion}

This paper provides an attainment method which is prepared in line with the guidelines indicated by NBA. The CO attainment carried out for VLSI Course from internal \& Board Exam results. PO attainment calculation carried out from sixth semester course and various surveys. Study reveals that although result was $100 \%$ for the course VLSI Design, the attainment was less for CO4 \& CO5. This analysis will help the faculty to plan new strategy for delivery, assessment \& students involvement in learning for improvement in ensuing semester.

\section{References}

[1] Surendar Rawat, Shruti Karkare ,Electronics and Communication Technology Department, V. E. S. Polytechnic, Sindhi Society, Chembur, Mumbai, India, An Empirical Study on Assessment of PO Attainment for a Diploma Program, International Journal of Advanced Research in Engineering and Technology ,(IJARET) Volume 6, Issue 11, Nov 2015.

[2] Zamri Mohamed, Mohd Yusof Taib, M.S. Reza,Malaysian Technical Universities, Assessment Method for Course Outcome and Program Outcome in Outcome Based Education (OBE), Conference on Engineering and Technology, June 28-29, 2010, Bayview Hotel, Melaka, Malaysia.

[3] Self Assessment Report (SAR) format diploma engineering programs from National Board of Accreditation.

[4] National Board of Accreditation Manual for Diploma Engineering Programmes (Tier-II) 